\title{
The composition of the material phase responsible for the self-healing of macro-cracks in asphalt mortar beams
}

Daniel Grossegger ${ }^{\mathrm{a}, \mathrm{b}}$, Alvaro Garcia ${ }^{\mathrm{a}}$ and Gordon Airey ${ }^{\mathrm{a} *}$

${ }^{a}$ Nottingham Transportation Engineering Centre, Department of Civil Engineering,

University of Nottingham, Nottingham, United Kingdom; ${ }^{b}$ School of Civil and

Transportation Engineering, South China University of Technology, Guangzhou, China

Provide full correspondence details here including e-mail for the *corresponding author:

Gordon.Airey@nottingham.ac.uk, Room C15/C16 Pavement Research Building,

University Park, Nottingham, NG7 2RD, United Kingdom

Word count:4056 


\title{
The composition of the material phase responsible for the self-healing of macro-cracks in asphalt mortar beams
}

\author{
The self-healing of asphalt is assumed to be a flow process where bitumen flows \\ into cracks to close these. Hence, the rheological behaviour of bitumen is one of \\ the main factors affecting the self-healing. Other important factors are the \\ damage history, healing duration and pressure, either due to a compressive \\ external force or internally through thermal expansion. Filler has a main \\ influence on the rheological behaviour of bitumen and the filler bitumen \\ interaction influences the asphalt properties. It is hypothesised that the material \\ flowing into cracks during self-healing is a mixture of bitumen and filler and \\ eventually fine aggregates. Therefore, the self-healing of macro-cracks in asphalt \\ mortar has been investigated in this paper. The self-healing ratio was determined \\ by mechanical testing and the self-healing was accelerated by an increase of \\ temperature to $100{ }^{\circ} \mathrm{C}$ during healing. Material draining from the asphalt mortar \\ beams into a horizontal gap, representing a crack, was found to be a mixture of \\ bitumen and aggregates. The mixture was proportional to the mixture of the \\ beams and an increasing self-healing ratio was observed with increasing bitumen \\ and filler content. To estimate a lower limit of the bitumen content of the mixture \\ (which would still allow self-healing), the thickness of bitumen films on glass \\ slides was combined with the surface area of the aggregates. For the mortar \\ mixture used in this study, a bitumen content of about $5.4 \mathrm{wt} \%$ was identified to \\ be the limit for self-healing due to the flow of a material phase in the mixture.
}

Keywords: macro-crack self-healing; mastic flow; asphalt mortar, flowable material phase: bitumen; limestone filler

\section{Introduction}

A continuous increase in traffic volume and the natural degradation of asphalt during ageing impose a burden on asphalt road structures. A result of this is a shortening of maintenance intervals and increasing maintenance effort (Petersen, 2009). Traditional asphalt road maintenance requires a large amount of natural resources and energy (Read \& Whiteoak, 2003) and at the same time produces construction waste. An 
environmental friendlier solution would be to utilise the self-healing potential of asphalt as a preventive and non-destructive method.

Self-healing is the ability to repair damaged parts and restore lost or reduced functionalities by the usage of inherent resources of the material (Wool, 2008). In asphalt, the self-healing is mainly attributed to its viscoelastic component bitumen. It is assumed that once a crack appears in the material, bitumen in the vicinity of the crack drains into it, filling the crack and hence, recovering the functionality that was lost or diminished (Á. García, 2012). The contribution of bitumen flow, or occasionally referred to as creep, towards the self-healing was identified at different material scale lengths. At the nano-scale, cracks in the catana or bee phase healed after heating samples to $45{ }^{\circ} \mathrm{C}$. The material filling the gaps is softer and is assumed to be from the surrounding peri or para phase (Nahar et al., 2013). The closing of gaps in bitumen at the micro-scale is faster for narrower gaps compared to wider gaps, driven by gravitational flow (Shen et al., 2016). The gap distance is a crucial factor, which is further supported by dynamic shear rheometer measurements of separated bitumen halves, showing an increase in force transmission as the gap distance decreased (Qiu et al., 2011). The self-healing rate, velocity of observed functional recovery, for bitumen and mortar at the meso-scale is related to the viscosity of the bitumen used (Á. García, 2012; Lv et al., 2017). Modifications with different polymers enhanced the healing of micro-cracks, though the healing of macro-cracks occurred at a slower rate compared to unmodified bitumen (Moreno-Navarro et al., 2017; Qiu et al., 2012). An important aspect is the interaction of filler and bitumen. An increasing filler content increases the viscosity and stiffness of the bitumen filler mixture (Romberg \& Traxler, 1947), known as mastic. Furthermore, the filler content influences the Newtonian transition temperature ( $\mathrm{Li}$ et al., 2018). The Newtonian transition temperature is identified for 
bitumen through measuring the changes in the viscoelastic behaviour of bitumen with temperature and makes the transition to a near Newtonian flow behaviour. This transition temperature was observed to coincide with the start of self-healing in asphalt mixtures (A. García et al., 2013). The filler type also has an influence on the healing activation energy calculated from fatigue tests on mastic. Active filler improved the healing of asphalt mastic compared to limestone filler, as the interface strength between filler and bitumen was improved (Sun et al., 2015). An optimal filler to bitumen ratio range was identified for several different filler types based on binder bond strength tests for healing in wet and dry conditions, workability, high temperature performance and cohesive bond strength. The optimum filler to bitumen ratio is between 0.33 and 0.35 (Zhang et al., 2019).

Since the viscosity of bitumen is temperature dependent, self-healing is affected by temperature. Below a certain threshold temperature healing does not occur, which is related to the Newtonian transition temperature (Liu et al., 2012; Menozzi et al., 2015). However, flow of bitumen and self-healing are observed at temperatures below the Newtonian transition temperature (Grossegger et al., 2018; Hamzah et al., 2012). Hence, a physical limitation is the glass transition temperature, marking the transition from a liquid to an amorphous solid state (Lesueur, 2009). An increase in temperature increases the self-healing of bitumen, mastic, mortar and asphalt, respectively. In addition, an increasing temperature entails a thermal expansion of the material. As the thermal expansion coefficient of bitumen is higher compared to the mineral aggregates, bitumen expands into voids, including cracks, thereby closing them (Grossegger \& Garcia, 2019a).

As the self-healing is imagined as bitumen flowing, minor attention has been paid to the interrelation of bitumen and filler as material draining into the crack or the 
limitation of bitumen being able to flow in asphalt. Therefore, this study determines the composition of material flowing into an artificial horizontal gap during the self-healing of a macro-crack in asphalt mortar beams. Furthermore, the critical bitumen content for the material to allow self-healing is estimated.

\section{Material and methods}

\subsection{Materials}

This study used an unmodified 70/100 pen bitumen, which had a softening point of $46.4{ }^{\circ} \mathrm{C}$ and a density of $1.02 \mathrm{~g} \cdot \mathrm{cm}^{-3}$. A continuous dense gradation of limestone aggregates with a maximum particle size of $4 \mathrm{~mm}$ and a density of $2.36 \mathrm{~g} \cdot \mathrm{cm}^{-3}$ was used as fine aggregates. The limestone filler had a density of $2.64 \mathrm{~g}^{\cdot} \mathrm{cm}^{-3}$. The mortar mixture was produced by heating the components to $180{ }^{\circ} \mathrm{C}$ and manually mixing the right proportions of each component together. The fine aggregates were mixed with $5 \mathrm{wt} \%$, $10 \mathrm{wt} \%, 15 \mathrm{wt} \%, 20 \mathrm{wt} \%$ and $28 \mathrm{wt} \%$ bitumen, which represent a bituminous mortar mixture with a maximum aggregate size of $4 \mathrm{~mm}$. As comparison a dense graded asphalt mixture by subtracting aggregates bigger than $4 \mathrm{~mm}$ and the bitumen film adhering to theses aggregates (van de Ven, 2012) would result in a bitumen content range for this mixture from $8 \mathrm{wt} \%$ to $28 \mathrm{wt} \%$. In addition, mixtures with a filler content of $1.5 \mathrm{wt} \%, 5 \mathrm{wt} \%, 8 \mathrm{wt} \%$ and $58 \mathrm{wt} \%$ and a bitumen content of $15 \mathrm{wt} \%$ together with an adjusted proportion of fine aggregates were produced. The mortar mixtures were used to manufacture prismatic beams of dimensions $100 \mathrm{~mm}$ x $30 \mathrm{~mm}$ x $30 \mathrm{~mm}$ with a $5 \mathrm{~mm}$ deep triangular notch in the middle.

To determine the effect of different concentrations of limestone filler on bitumen, mastics with filler to bitumen ratios of 9:91, 50:50 and 70:30 were produced. 


\subsection{Macro-crack self-healing in asphalt mortar beams}

A brittle macro-crack (complete fracture of the asphalt mortar beams) was generated by breaking the beams after storing them at $-17^{\circ} \mathrm{C}$ through three-point breaking tests performed in an Instron testing machine. The initial breaking force was recorded for the calculation of the self-healing ratio. The beam halves were let to rest at ambient temperature of $20^{\circ} \mathrm{C}$ for 16 hours.

In order to enhance the self-healing and shorten the healing duration, the broken beam halves were assembled and placed inside a two-parts mould made of silicone rubber and further placed inside a preheated convection oven at $100{ }^{\circ} \mathrm{C}$. After the healing duration in the oven, which varied from 1 to 180 minutes, the beams were removed from the oven and the surface temperature of the beams was measured through an infrared camera (micro-epsilon, TIM160). To prevent further healing, the beams were stored at a temperature of $-17^{\circ} \mathrm{C}$. Since the time between removal of the oven and termination of the healing due to reaching a temperature below the healing threshold temperature was not accounted for, the healing time refers to the duration of the samples in the oven. The breaking force after healing was measured by means of three-point breaking again. The self-healing ratio was defined as the ratio of breaking force after healing to the initial breaking force.

\subsection{Material flow into an artificial gap}

The two-part mould, which was used to heal the asphalt mortar beams, was prepared to have a gap of approximately $1 \mathrm{~mm}$, see Figure 1 . The length of the material draining into the gap, herein after referred to as flow length (see detailed section in Figure 1), during the healing duration was measured. In addition, the material in the gap was collected and the mineral particles were separated to identify the composition of the flowable mixture material, which potentially is responsible for the crack healing. The 
material in the gap was separated from the beam by breaking or cutting at low temperatures. The initial weight of the collected material of each beam was recorded and placed in a beaker with $20 \mathrm{ml}$ of methyl benzene (Fisher Scientific, 99\% purity). After a period of 24 hours, all bitumen was dissolved and the content was transferred onto a filter paper (Fisherbrand QT210, fine retention and slow filtration rate). The filtrate was collected in a round bottom flask. The filter cake with the filter paper was placed inside an extractor to remove any further bitumen content adhering to the aggregates. The extraction process was performed until the filter paper was clear of dark stains and the filtrate left no stains on a glass slide after evaporation. The weight of the filter cake was recorded after removing any solvent in an oven at $105^{\circ} \mathrm{C}$. Moreover, the filter cake was sieved through two sieves with a mesh aperture of $1 \mathrm{~mm}$ and $63 \mu \mathrm{m}$ to determine the particle size ratio of the separated aggregates. Aggregate content below $63 \mu \mathrm{m}$ is referred to as filler, content between $63 \mu \mathrm{m}$ and $1 \mathrm{~mm}$ as fine particles and particles with size bigger than $1 \mathrm{~mm}$ are referred to as particles $>1 \mathrm{~mm}$.

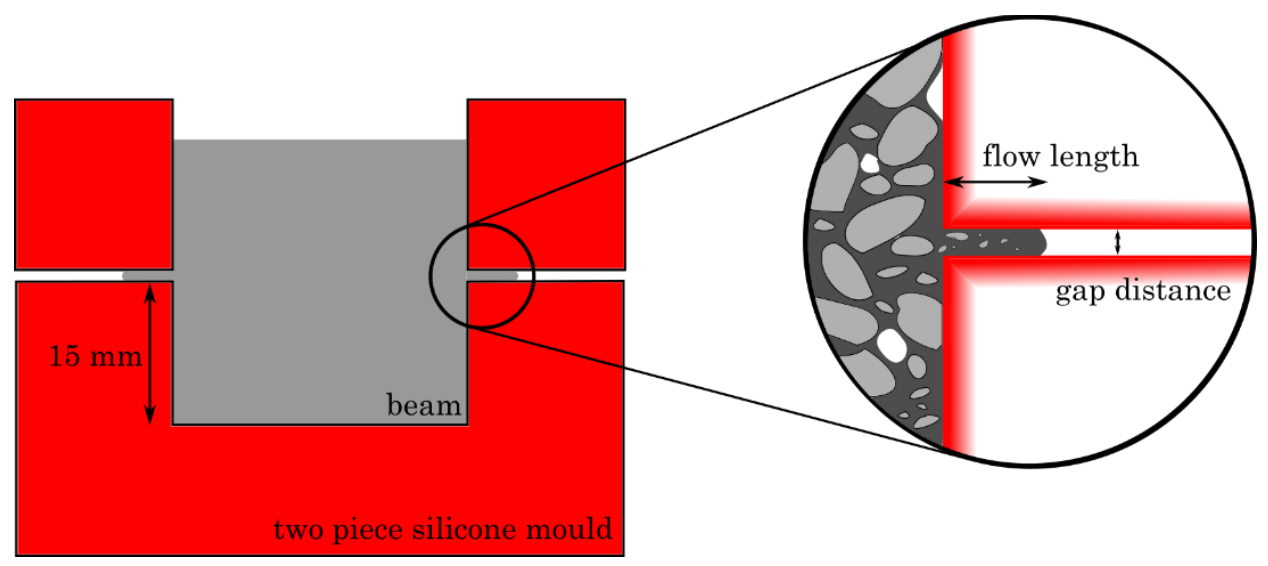

Figure 1. Illustration of the flow into the artificial gap between the two-parts silicone mould. The gap distance was approximately $1 \mathrm{~mm}$ and the flow length was measured (enlarged section).

\subsection{Self-drainage of bitumen and mastic from a vertical surface}

The film thickness of bitumen and mastic due to gravitational flow was determined in 
order to estimate the amount of bitumen or mastic in the mixture, which could flow between bigger aggregates. Therefore, bitumen or mastic was heated to $160{ }^{\circ} \mathrm{C}$ and a glass slide (76 mm x $26 \mathrm{~mm}$, Thermo Scientific) was coated with a thick film of approximately $2 \mathrm{~mm}$ over a length of $60 \mathrm{~mm}$, as shown in Figure 2. The bitumen or mastic coated glass slide was placed vertically inside an oven at temperatures of $60{ }^{\circ} \mathrm{C}$, $80{ }^{\circ} \mathrm{C}, 100{ }^{\circ} \mathrm{C}$ and $120^{\circ} \mathrm{C}$, respectively. The coated glass slides remained in the oven until no further dropping from the glass slide was observed. The thickness was measured at $15 \mathrm{~mm}$ and $45 \mathrm{~mm}$ from the upper edge of the film. Each temperature was repeated four times.

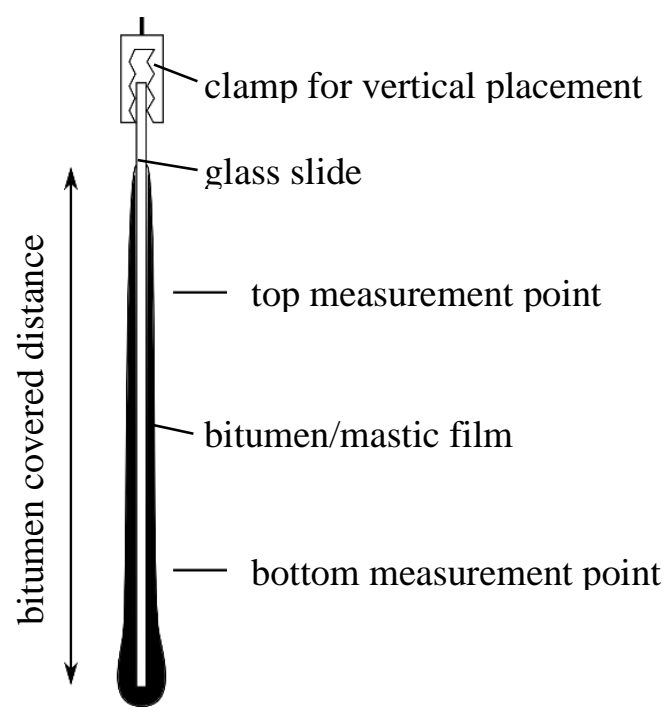

Figure 2. Illustration of the bitumen/mastic coated glass slide, which was placed vertically inside an oven and held in place by a clamp. Indicated are the measurement points at which the film thickness was determined.

\subsection{Viscosity}

The viscosity was determined by means of a rotating spindle viscometer (Brookfield) (British Standards Institution, 2018). $9.5 \mathrm{ml}$ of bitumen or mastic was poured into a metal test cylinder and the spindle was lowered into the liquid. The viscosity was recorded in the temperature range from $60{ }^{\circ} \mathrm{C}$ to $160{ }^{\circ} \mathrm{C}$ in $10{ }^{\circ} \mathrm{C}$ intervals. Since the 
addition of filler to bitumen increases the viscosity, the lower temperature limit was adjusted for mastic mixtures depending on the viscometer's torque limitations.

\subsection{Specific surface area of the aggregates and filler}

The specific surface area of the aggregates and the filler was measured through the dynamic vapour sorption method. About $1 \mathrm{~g}$ of material was weighed into one pan of the balance system (surface measurement system). The test sequence consisted of a drying phase at $120{ }^{\circ} \mathrm{C}$, recording the exact weight of the sample at the end of the drying phase, followed by a stepwise increase of partial water pressure in $10 \%$ steps from $0 \%$ to $90 \%$. Each step lasted for 60 minutes. The weight change was constantly recorded and converted to a specific surface area based on the Brunauer-Emmett-Teller (BET) theory using the standard software of the instrument.

\section{Results and discussion}

\subsection{Macro-crack self-healing}

The surface temperatures of the asphalt mortar beams increased due to inducing healing in an oven at $100^{\circ} \mathrm{C}$. Due to the same bitumen content being used, the surface temperature increase was similar for different amounts of filler, as the thermal conductivity and heat capacity did not change significantly. An increase of the bitumen content caused a noticeable slowing down of the surface temperature increase, which was attributed to the lower heat conductivity of bitumen compared to mineral aggregates (Read \& Whiteoak, 2003). The equilibrium surface temperature was independent of filler and bitumen content, as it only depended on the oven temperature.

The self-healing rate increased with increasing bitumen content, whereas, a slight decrease in the self-healing rate with increasing filler content was noticed, shown in Figure 3. Due to the heat induced self-healing, thermal expansion contributed to the 
self-healing and caused a similar self-healing development (Grossegger \& Garcia, $2019 b)$. Furthermore, the filler amount did not affect the self-healing ratios of the maximum self-healing region, which was reached after approximately 30 minutes. The maximum self-healing region is the maximum self-healing ratio under consideration of statistical variability. Hence, the maximum self-healing region occurs when the selfhealing rate becomes zero or reaches a value close to zero. It can be a constant region, as shown in Figure 3 or in certain cases a decrease in the self-healing ratio is observed, which is related to binder drainage or geometrical/structural changes (Á. García, 2012; Gómez-Meijide et al., 2016).
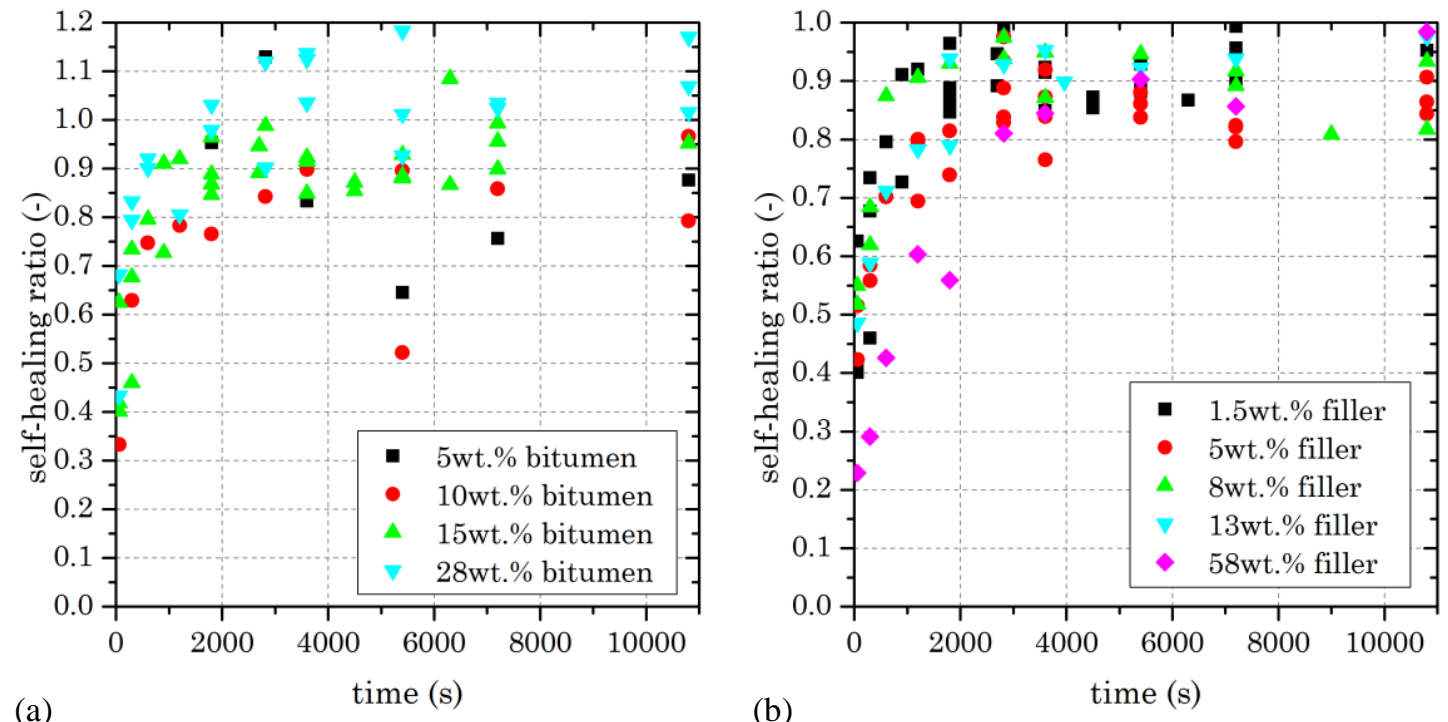

Figure 3. The development of self-healing ratios with time for different bitumen contents (a) and filler contents (b).

The self-healing ratios greater than one for bitumen contents of $20 \mathrm{wt} \%$ and $28 \mathrm{wt} \%$ was attributed to the higher deformability of the beams due to the increased bitumen content and the thermal expansion due to the increase in temperature. Since the beams were supported by moulds, material and geometry loss was prevented. Figure 4 shows the initial breaking force of beams and the maximum self-healing range of asphalt mortar beams with different bitumen content. The maximum self-healing range 
increased with increasing bitumen content. Whereas, the initial breaking force had a maximum at a bitumen content of $15 \mathrm{wt} \%$. The fracture surface showed that for a low bitumen content the fracture propagates mainly as an adhesive crack, at the interface of the bitumen and aggregates. The adhesive crack and the high air voids content results in a lower breaking force. As the bitumen content increases, the air voids content decreases and a combined adhesive and cohesive fracture was observed. The reduction of the breaking strength for higher bitumen content is due to the increase of cohesive fracture area of the bitumen and the decrease of aggregates in the fracture pathway to hinder and redirect crack propagation (Zeng et al., 2014). The self-healing is less affective for lower bitumen contents, as less bitumen is available to close the crack. As bitumen content increases, the self-healing increased due to the increased amount of bitumen available to close cracks. The maximum self-healing ratio is approaching 1 (completely healed), as fewer aggregates are fractured with increasing bitumen content until only cohesive bitumen fracture remains to be healed.



Figure 4. Maximum self-healing ratio range and the initial breaking force of mortar beams with different bitumen contents. The Person correlation coefficient for the linear 
increase of self-healing ratio with bitumen content is 0.96 . The initial breaking force is fitted by a parabolic shape $\left(\mathrm{R}^{2}=0.97\right)$. The error bars represent the standard deviation.

\subsection{Material flow into an artificial horizontal gap}

No material drained into the artificial gap created by the two-part silicone mould for asphalt mortar beams with bitumen contents below $25 \mathrm{wt} \%$ and no added filler. Since the mortar mixture included air voids, which decreased with increasing bitumen or filler content, a vertical flow due to gravity with no horizontal component due to the sufficient space was assumed for mortar mixtures with no added filler content. Drainage of material into the gap was observed for the varying amounts of filler content above $1,5 \mathrm{wt} \%$ and beams with a bitumen content of $28 \mathrm{wt} \%$. The distance covered by the material increased linearly with advancing healing time, as shown in Figure 5(a). This is in accordance with a horizontal capillary flow, where flow length is proportional to time. Furthermore, the similar starting time and flow progression for mixtures with $5 \mathrm{wt} \%, 8 \mathrm{wt} \%$ and $13 \mathrm{wt} \%$ filler indicates that thermal expansion influenced the flow of material into the gap. Hence, difference in the flow due to different viscosities potentially were reduced, similar to the self-healing progression.

Since the gap distance was approximately $1 \mathrm{~mm}$, mainly aggregates with a diameter below $1 \mathrm{~mm}$ could drain into the gap. The separation of aggregates from the drained material is shown in Figure 5(b). The filler content of the drained material increased linearly with the filler content of the mortar beams. The bitumen content decreased linearly with the filler content, implying that the drainable material composition depends on the mixture composition. For a filler content of $58 \mathrm{wt} \%$, particles $>1 \mathrm{~mm}$ were detected in the drained material. It was assumed that these particles were partly in the gap opening and during the removal process added to the drained material, and the gap distance increased due to thermal expansion of the silicone during the heat induced 
healing in the oven, respectively.
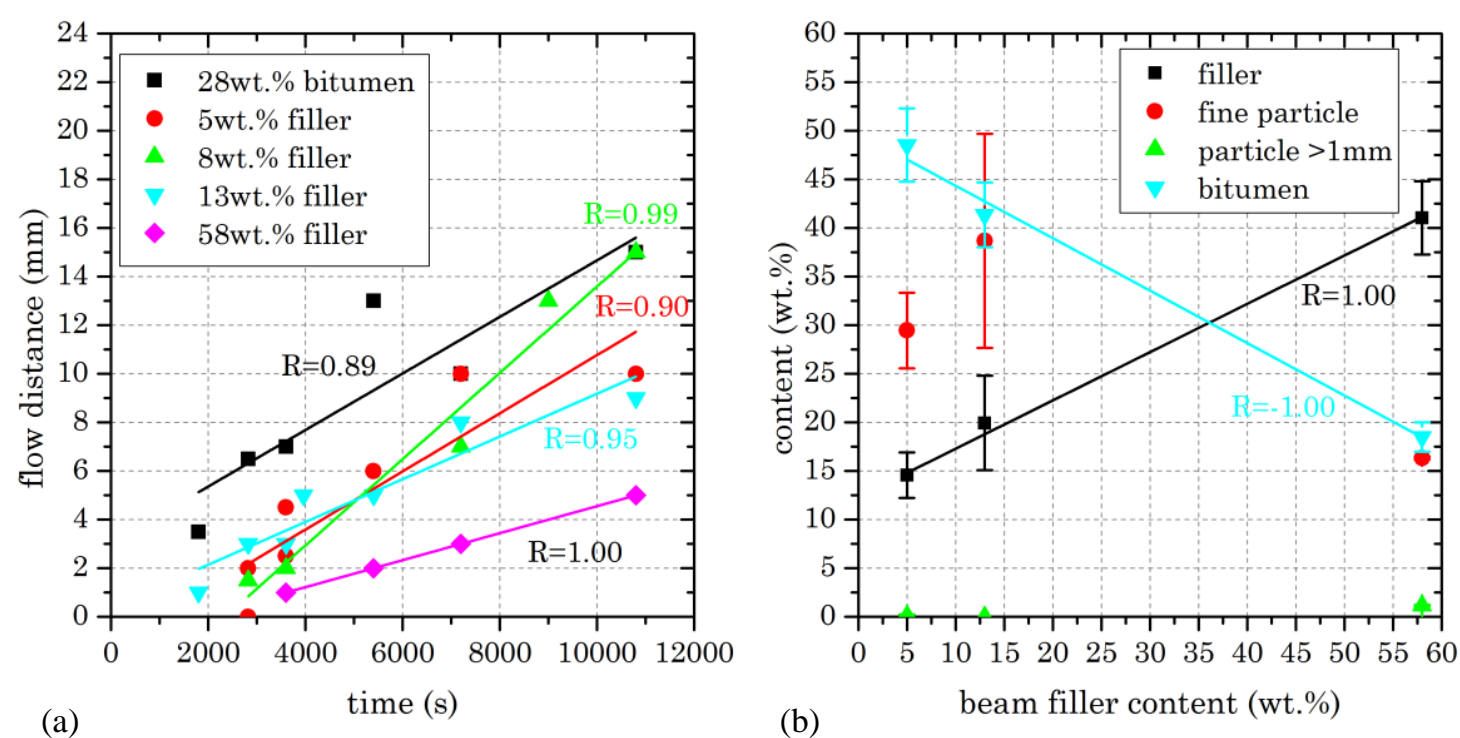

Figure 5. Flow length of the material drained into the artificial horizontal gap (a) and the relation between filler content of the asphalt mortar beam and the composition of the drained material (b). The error bars represent the standard deviation.

\subsection{Bitumen and mastic film thickness on a vertical surface}

The remaining film on a surface due to gravitational flow depends on the location of the film, time and viscosity (Ali et al., 2016). The following equation can be used to calculate the film thickness of a liquid draining off a vertical surface (Jeffreys, 1930):

$$
h=\left(\frac{\eta x}{\Delta \rho g t}\right)^{0.5}
$$

where $h$ is the film thickness $(\mathrm{m}), \eta$ is the viscosity $(\mathrm{Pa} \cdot \mathrm{s}), x$ is the vertical distance from the beginning of the film (m), $\Delta \rho$ is the density difference $\left(\mathrm{kg} \cdot \mathrm{m}^{-3}\right), g$ is the gravitational acceleration $\left(\mathrm{m}^{\cdot} \mathrm{s}^{-2}\right)$ and $t$ is time $(\mathrm{s})$. The exponent of 0.5 is occasionally replaced by a characteristic parameter, which was identified to be between 0.642 and 0.645 for mineral oil (Morey, 1940).

The bitumen film thickness decreased as temperature increased. Since the viscosity of bitumen is temperature dependent, Figure 6(a) shows the increase of 
bitumen film thickness with increasing viscosity. The measurements at the top measurement point were nearly independent of the viscosity, indicating that the bitumen film is an adsorption film remaining on the surface. The bottom measure point showed a linear correlation as indicated by Eq. 1. The drainage of mastic revealed that the adsorption film increased in thickness with increasing filler content, as shown in Figure 6(b). This is in accordance with Eq. 1. An increase in filler content increases the viscosity and therefore the film thickness increases. A significant difference in film thickness was found for the temperature of $60^{\circ} \mathrm{C}$. The correlation was only indicated at higher temperatures. Hence, the film thickness for temperatures above $80^{\circ} \mathrm{C}$ was attributed to the filler adhering to the surface through the adhesive properties of the bitumen. Whereas, at $60^{\circ} \mathrm{C}$ the viscosity of the mastic determines the film thickness.
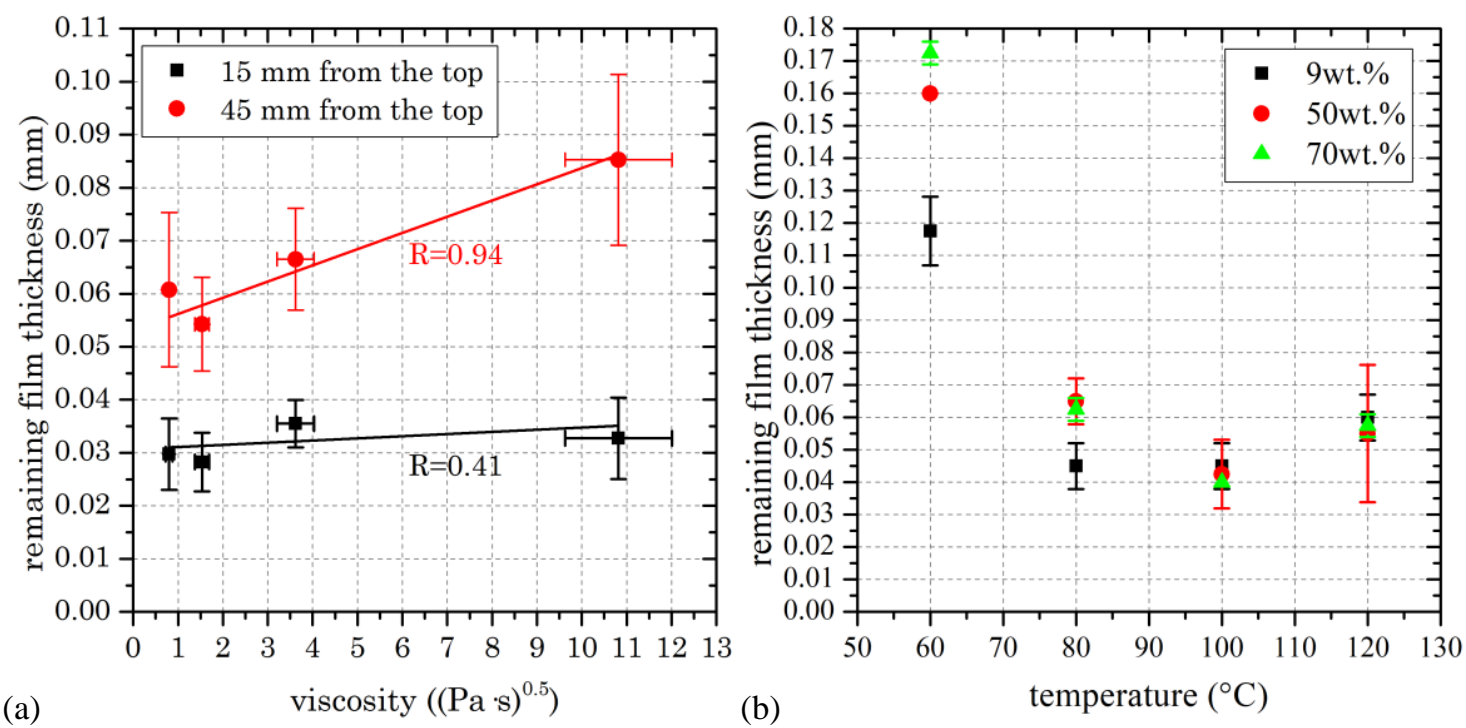

Figure 6. Remaining film thickness of bitumen (a) and mastic (b). Thickness of the top and bottom measurement points are provided for bitumen and plotted against the square root of the viscosity, as the proportional relationship in Eq. 1 suggests. The mastic film thickness for different filler content was measured at the bottom measurement point (45 $\mathrm{mm}$ from the beginning of the film). The error bars represent the standard deviation. 


\subsection{Self-healing limit due to flow}

Since self-healing is assumed to be a flow process of material into cracks with an adhesive bitumen film remaining around the aggregates, the minimum bitumen content of a mixture to exhibit self-healing properties based on flow can be calculated. The measured adhering film thickness from the self-draining test was $30 \mu \mathrm{m} \pm 4 \mu \mathrm{m}$ for bitumen and $43 \mu \mathrm{m} \pm 14 \mu \mathrm{m}$ for mastic. The bitumen film thickness is in the same range as the thickness corresponding to the highest bonding strength of the interlayer bonding of mortar films, which is in the range of $20 \mu \mathrm{m}$ to $36 \mu \mathrm{m}$ (Mo et al., 2009). The specific surface area of the aggregates used was $1851 \mathrm{~m}^{2} \cdot \mathrm{kg}^{-1}$ and the specific surface area of the filler was $4583 \mathrm{~m}^{2} \cdot \mathrm{kg}^{-1}$. The minimum amount of bitumen was calculated to be $5.4 \mathrm{wt} \%$ $\pm 0.7 \mathrm{wt} \%$ for the aggregates used in this study. Assuming a mastic film covering the aggregates instead of a bitumen film, the bitumen amount decreases linearly as the filler content of the mastic increases. For a mixture containing $5 \mathrm{wt} \%$ filler, the minimum bitumen content is $6.6 \mathrm{wt} \% \pm 2.0 \mathrm{wt} \%$ and for a mixture containing $58 \mathrm{wt} \%$ filler, the minimum bitumen content reduces to $2.8 \mathrm{wt} \% \pm 0.8 \mathrm{wt} \%$. These calculations neglect the possibility of trapped bitumen or mastic in the contact points of aggregates due to capillary forces. Furthermore, the asphalt mortar mixture with $5 \mathrm{wt} \%$ bitumen exhibited self-healing, which was attributed to the adhesion of the crack surfaces due to initial contact and the increase of the contact areas due to surface tension (Sun et al., 2017) and thermal expansion.

\section{Conclusions}

The self-healing of macro-cracks in asphalt mortar beams with different bitumen and filler contents was evaluated. In addition, the potential material draining into cracks was identified and the minimum bitumen content for a mixture based on the bitumen film 
adhering to aggregates was estimated. Based on the results and analysis the following conclusions were made:

- The bitumen content slightly influenced the self-healing rate, due to the contribution of thermal expansion, and influenced the maximum self-healing region. The maximum self-healing region tended to shift to higher self-healing ratio values with increasing bitumen content. The initial breaking force showed a parabolic correlation to the bitumen content. The decrease in the breaking force positively affected the self-healing, as the cohesive fracture surface increased.

- Only a high amount of filler $(58 \mathrm{wt} \%)$ showed a reduction in the self-healing rate. The maximum self-healing region was unaffected by the filler content.

- A bitumen rich material drained into the artificial horizontal gap, though only from mixtures with a filler content above $5 \mathrm{wt} \%$ or a bitumen content of $28 \mathrm{wt} \%$. This is partly related to the void content of the mixture affecting the drainage and the experimental set up. The filler content of the drainage material was proportional to the filler content of the mortar mixture. The bitumen content decreased with increasing filler content. In addition, the gap distance of $1 \mathrm{~mm}$ limited the size of the aggregates entering the gap. A similar selective occurrence for asphalt is assumed, as the grain structure would only allow aggregates of a certain size to move in the flow process.

- A minimum bitumen content for self-healing was calculated, which was found for the aggregates used to be $5.4 \mathrm{wt} \%$ bitumen. However, the mixture with bitumen content of $5 \mathrm{wt} \%$ still showed self-healing. This was partly attributed to the initial adhering of bitumen at the fracture surface, the increase of contact area due to surface tension and potential rearrangements of aggregates during 
the healing duration at increased temperature, resulting in a local deformation of the material. The minimum bitumen content was assumed to be filler sensitive and linearly decreased from $6.6 \mathrm{wt} \%$ bitumen for $5 \mathrm{wt} \%$ filler to $2.8 \mathrm{wt} \%$ bitumen for $58 \mathrm{wt} \%$.

\section{Acknowledgements}

The authors like to thank the Faculty of Engineering at the University of Nottingham for granting one of the authors a $\mathrm{PhD}$ research fellowship.

\section{References}

Ali, A., Underwood, A., Lee, Y.-R., \& Wilson, D. I. (2016). Self-drainage of viscous liquids in vertical and inclined pipes. Food and Bioproducts Processing, 99, 3850.

British Standards Institution. (2018). Bitumen and bituminous binders-Determination of dynamic viscosity of bituminous binder using a rotating spindle apparatus (BS EN 13302:2018).

García, Á. (2012). Self-healing of open cracks in asphalt mastic. Fuel, 93, 264-272.

García, A., Bueno, M., Norambuena-Contreras, J., \& Partl, M. N. (2013). Induction healing of dense asphalt concrete. Construction and Building Materials, 49, 1-7.

Gómez-Meijide, B., Ajam, H., Lastra-González, P., \& Garcia, A. (2016). Effect of air voids content on asphalt self-healing via induction and infrared heating. Construction and Building Materials, 126, 957-966.

Grossegger, D., \& Garcia, A. (2019a). Influence of the thermal expansion of bitumen on asphalt self-healing. Applied Thermal Engineering, 156, 23-33.

Grossegger, D., \& Garcia, A. (2019b). Influence of the thermal expansion of bitumen on asphalt self-healing. Applied Thermal Engineering, 156, $23-33$. 
Grossegger, D., Gomez-Meijide, B., Vansteenkiste, S., \& Garcia, A. (2018). Influence of rheological and physical bitumen properties on heat-induced self-healing of asphalt mastic beams. Construction and Building Materials, 182, 298-308.

Hamzah, M. O., Hasan, M. R. M., \& van de Ven, M. (2012). Permeability loss in porous asphalt due to binder creep. Construction and Building Materials, 30, 1015.

Jeffreys, H. (1930). The draining of a vertical plate. Mathematical Proceedings of the Cambridge Philosophical Society, 26, 204-205.

Lesueur, D. (2009). The colloidal structure of bitumen: Consequences on the rheology and on the mechanisms of bitumen modification. Advances in Colloid and Interface Science, 145(1), 42-82.

Li, C., Wu, S., Tao, G., \& Xiao, Y. (2018). Initial self-healing temperatures of asphalt mastics based on flow behavior index. Materials, 11(6), 917.

Liu, Q., Schlangen, E., \& van de Ven, M. (2012). Induction healing of porous asphalt concrete beams on an elastic foundation. Journal of Materials in Civil Engineering, 25(7), 880-885.

Lv, Q., Huang, W., Zhu, X., \& Xiao, F. (2017). On the investigation of self-healing behavior of bitumen and its influencing factors. Materials \& Design, 117, 7-17.

Menozzi, A., Garcia, A., Partl, M. N., Tebaldi, G., \& Schuetz, P. (2015). Induction healing of fatigue damage in asphalt test samples. Construction and Building Materials, 74, 162-168.

Mo, L., Huurman, M., Wu, S., \& Molenaar, A. A. A. (2009). Ravelling investigation of porous asphalt concrete based on fatigue characteristics of bitumen-stone adhesion and mortar. Materials \& Design, 30(1), 170-179. 
Moreno-Navarro, F., Ayar, P., Sol-Sánchez, M., \& Rubio-Gámez, M. C. (2017).

Exploring the recovery of fatigue damage in bituminous mixtures at macro-crack level: the influence of temperature, time, and external loads. Road Materials and Pavement Design, 18(sup2), 293-303.

Morey, F. C. (1940). Thickness of a liquid film adhering to surface slowly withdrawn from the liquid. Journal of Research of the National Bureau of Standards, 25, 385393.

Nahar, S. N., Schmets, A. J. M., Scarpas, A., \& Schitter, G. (2013). Temperature induced healing in strained bituminous materials observed by atomic force microscopy. ICSHM 2013: Proceedings of the 4th International Conference on Self-Healing Materials, Ghent, Belgium, 16-20 June 2013.

Petersen, J. C. (2009). A review of the fundamentals of asphalt oxidation: chemical, physicochemical, physical property, and durability relationships. Transportation Research Circular, E-C140, 68.

Qiu, J., van de Ven, M. F. C., Wu, S. P., Yu, J. Y., \& Molenaar, A. A. A. (2011). Investigating self healing behaviour of pure bitumen using dynamic shear rheometer. Fuel, 90(8), 2710-2720.

Qiu, J., van de Ven, M., Wu, S., Yu, J., \& Molenaar, A. (2012). Evaluating self healing capability of bituminous mastics. Experimental Mechanics, 52(8), 1163-1171.

Read, J., \& Whiteoak, D. (2003). The shell bitumen handbook. Thomas Telford.

Romberg, J. W., \& Traxler, R. N. (1947). Rheology of asphalt. Journal of Colloid Science, 2(1), 33-47.

Shen, S., Lu, X., Liu, L., \& Zhang, C. (2016). Investigation of the influence of crack width on healing properties of asphalt binders at multi-scale levels. Construction and Building Materials, 126, 197-205. 
Sun, D., Lin, T., Zhu, X., \& Cao, L. (2015). Calculation and evaluation of activation energy as a self-healing indication of asphalt mastic. Construction and Building Materials, 95, 431-436.

Sun, D., Sun, G., Zhu, X., Pang, Q., Yu, F., \& Lin, T. (2017). Identification of wetting and molecular diffusion stages during self-healing process of asphalt binder via fluorescence microscope. Construction and Building Materials, 132, 230-239.

van de Ven, M. F. C. (2012). The Influence of Ageing on the Fatigue and Healing Properties of Bituminous Mortars. Procedia-Social and Behavioral Sciences, 53, $256-265$.

Wool, R. P. (2008). Self-healing materials: a review. Soft Matter, 4(3), 400-418.

Zeng, G., Yang, X., Yin, A., \& Bai, F. (2014). Simulation of damage evolution and crack propagation in three-point bending pre-cracked asphalt mixture beam. Construction and Building Materials, 55, 323-332.

Zhang, H., Li, H., Abdelhady, A., Mo, D., Yang, B., \& Harvey, J. (2019). Optimum Filler-Bitumen Ratio of Asphalt Mortar Considering Self-Healing Property. Journal of Materials in Civil Engineering, 31(8), 4019166. 